\title{
Vibrational Relaxation of Functional Groups in dAMP Molecules Probed with UV Resonance Raman Spectroscopy
}

\author{
CRISTINA M. MUNTEAN ${ }^{1 * \#, ~ I O A N ~ B R A T U ~}{ }^{1 * *}$, BERND WALKENFORT ${ }^{2}$, MOHAMMAD SALEHI ${ }^{2}$, \\ SIMINA A. PURCARU ${ }^{3}$, ANTONIO HERNANZ ${ }^{4}$ \\ ${ }^{1}$ National Institute for Research \& Development of Isotopic and Molecular Technologies, 67-103 Donat Str., 400293, \\ Cluj-Napoca, Romania \\ ${ }^{2}$ Universität Duisburg-Essen, Fakultät für Chemie, Physikalische Chemie I, Universitätsstrasse 5, 45141 Essen, Germany \\ ${ }^{3}$ Transilvania University of Brasov, 1 Universitǎţii Str., 500068, Brasov, Romania \\ ${ }^{4}$ UNED, Departamento de Ciencias y Técnicas Fisicoquímicas, Paseo de la Senda del Rey, 9, E-28040 Madrid, Spain
}

Dynamical properties of functional groups in 2'-deoxyadenosine-5'-monophosphate (dAMP) compound, were identified by $U V$ resonance Raman spectroscopy (UVRR), upon varying nucleotide concentration in aqueous solution (200-600 $\mu \mathrm{M}$ ). The studied full-widths at half-maximum (fwhm's) were found between $13-21 \mathrm{~cm}^{-1}$ and the corresponding global relaxation times were faster than 0.817 ps and slower than $0.506 \mathrm{ps}$. Also, the band around $1430 \mathrm{~cm}^{-1}(C 4 N 9-\delta C 8 H)$ in the UV resonance Raman spectrum of dAMP molecule at $400 \mu M$ concentration in aqueous solution, was selected for vibrational band shape analysis through time correlation function $(C F)$ concept. Current theories developed for vibrational dephasing (Kubo-Rothschild and Oxtoby) have been applied to this profile and relevant relaxation parameters have been obtained and discussed. The best fit parameters for this dissipation channel of the vibrational excitation energy were established. To our knowledge this is the first UVRR study on nucleotide vibrational band shape analysis through time correlation function concept.

Keywords:2'-deoxyadenosine-5'-monophosphate, UV resonance Raman spectroscopy, time correlation function, vibrational relaxation, vibrational dephasing

Nucleic acids components play an important role in different stages of the biological processes. Inside the living cell, the static structures of nucleic acids and their constituents must function in dynamic processes, through participation in specific interactions with other molecules. The dynamics of nucleic acids and their components is crucial for biological function of these biomolecules, particularly playing a significant role in the molecular recognition of DNA-protein and DNA-ligand systems [1]. It is clear that the understanding of the complex processes of DNA biopolymer in vivo requires the detailed knowledge of its dynamics as a function of the molecular relaxation characterizing its components.

Insight knowledge about the molecular dynamics processes involved in liquids mixtures can be obtained by Raman spectroscopy [2]. However, a simple analysis of the vibrational half bandwidths is insufficient for comprehending the dynamics of a molecule in liquid. Therefore, in the case of Raman profiles, it is necessary to pass from the spectral into a time range and to consider the time correlation functions (CFs) of vibrational and orientational relaxation, the Fourier transforms of band contours detected in the Raman spectra. From this stand point, Rabadanov et al. [3] studied the dephasing of totally symmetrical vibration $v_{1}\left(A_{1}\right)$ and overtone $v_{2}(E)$ of the perchlorate ion in molten lithium perchlorate. Their findings show that vibrational dephasing is the main factor of the broadening of isotropic spectral bands and in this particular case, dephasing behaves according to the Gaussian-Markovian mechanism [3].

The sensitivity of vibrational spectroscopy to intermolecular forces and its potential to probe solute-solvent interactions were investigated by Ramakrishnan et al. in substituted benzaldehyde binary mixtures [4]. In this context, the vibrational $\mathrm{CF}$ of the $v(\mathrm{C} \equiv \mathrm{N})$ mode, proved the presence of a dynamical regime in the system, positively influenced by the temperature increase [5].

Most recently, studies concerning the role of microenvironment and hydrodynamic forces or of the dilution effect on the vibrational relaxation processes were carried out by Kalampounias et al. on pyridine-water complexes [6] and on $\mathrm{PbCl}_{2}-\mathrm{KCl}$ ionic liquids [7], respectively. By taking into consideration vibrational second moments variation, dephasing times or the vibrational relaxation rate as guiding parameters, they concluded that the microenvironment plays an important role in the vibrational relaxation processes (in correlation to solvent viscosity, density, refractive index, etc.).

*email: cmuntean@itim-cj.ro; ioan.bratu@itim-cj.ro

REV.CHIM.(Bucharest) $\bullet 11$ no. $1 \bullet 2020$
\# Authors with contributed equall to this work 
In particular, advances in this research field are contributing to build an interesting picture of the molecular dynamics of nucleic acids, their derivatives and components, e. g. the study carried out by Kozich et al. [8]. The symmetric stretching mode, $v_{\mathrm{s}}\left(\mathrm{PO}_{3}{ }^{2-}\right)$, of several mononucleotides (5'-GMP, 5'-CMP and 5'-dCMP) have been studied in $\mathrm{H}_{2} \mathrm{O}$ and ${ }^{2} \mathrm{H}_{2} \mathrm{O}$ solutions, at different concentrations and temperatures by infrared spectroscopy [9-12]. Studies on the fwhm's of calf-thymus DNA Raman bands revealed their sensitivity to $\mathrm{pH}$, as well as to the presence and concentration of different metal cations [13]. Besides, our group investigated the vibrational relaxation of a 22-mer duplex DNA, as probed with UVRR spectroscopy [14]. Resonance Raman spectroscopy (RRS) is a useful technique employed to obtain experimental data on molecular relaxation dynamics [15].

All these research findings underline the complex nature of the vibrational relaxation processes in different molecular systems.

In the followings, we report an UV resonance Raman spectroscopic study on the subpicosecond dynamics of functional groups in 2'-deoxyadenosine-5'-monophosphate (dAMP) in aqueous solutions, at different concentrations. We will concentrate on the full-widths at half-maximum (fwhm's) and on the corresponding global relaxation times. The existence of molecular concentration-dependent processes with biological relevance, justifies the study of biomolecular dynamics upon variation of this parameter. Also, square root of concentration-dependences of the half bandwidths of different vibrational modes, can give information on the most efficient relaxation mechanism which takes place in aqueous system $[11,16-20]$. Besides, the $1430 \mathrm{~cm}^{-1}$ UVRR band characterizing $v(\mathrm{C} 4 \mathrm{~N} 9-\delta \mathrm{C} 8 \mathrm{H})$ oscillator of dAMP molecule $(400 \mu \mathrm{M})$, was selected for band shape analysis. Vibrational dephasing accomplishes an efficient vibrational relaxation of this mode. Theoreticals models (Kubo-Rothschild and Oxtoby) for this process have yielded significant relaxation parameters.

\section{Experimental part}

2'-deoxyadenosine-5'-monophosphate (D-6375 Sigma) has been used without further purification. dAMP molecules were dissolved in aqueous solutions (10 mM Bistris, $50 \mathrm{mM} \mathrm{NaCl}, \mathrm{pH} 6.4)$, at different concentrations: $200 \mu \mathrm{M}, 300 \mu \mathrm{M}$, $400 \mu \mathrm{M}, 500 \mu \mathrm{M}$ and $600 \mu \mathrm{M}\left(2 \cdot 10^{-4}, 3 \cdot 10^{-4}, 4 \cdot 10^{-4}, 5 \cdot 10^{-4}, 6 \cdot 10^{-4} \mathrm{~mol} \cdot \mathrm{dm}^{-3}\right)$.

The UV resonance Raman measurements were done at the University of Osnabrück, Osnabrïck, Germany. Continuous wave Raman equipment described in detail elsewhere [14,21] was employed for recording the UVRR spectra. All UV resonance Raman profiles of dAMP molecules were registered in the same experimental conditions.

\section{Data treatment}

Data treatment was applied as described in Muntean et al. [14].

\section{Results and discussions}

In this work the subpicosecond dynamics of dAMP functional groups, in the case of relaxation processes which take place in solution are of interest.

Molecular structure of 2'-deoxyadenosine-5'-monophosphate is presented elsewhere [22]. The $275 \mathrm{~nm}$-excited UV resonance Raman spectra of dissolved dAMP molecules, at different concentrations, are presented in Figure 1. Spectrastructure correlations were established for the UV resonance Raman profiles of the investigated compound [23,24].

\section{dAMP concentration-dependences of full-widths at half-maximum and global relaxation times}

The selection of the concentration in the interval $2 \cdot 10^{-4}-6 \cdot 10^{-4} \mathrm{~mol} \cdot \mathrm{dm}^{-3}$ is depending on the hypothesis to work with an isolated molecule, i. e. the relaxation processes are related to an isolated molecule present in the aqueous medium. Besides, appropriated experimental conditions have been selected in relation with the hypothesis established in the theoretical models, in order to apply the vibrational dephasing models (diluted concentrations to avoid intermolecular interactions). A possible aggregation process of the nucleotide at concentrations higher than $\sim 0.3 \mathrm{~mol} \mathrm{dm}^{-3}$ was previously detected (refs [11-12] and references therein). 

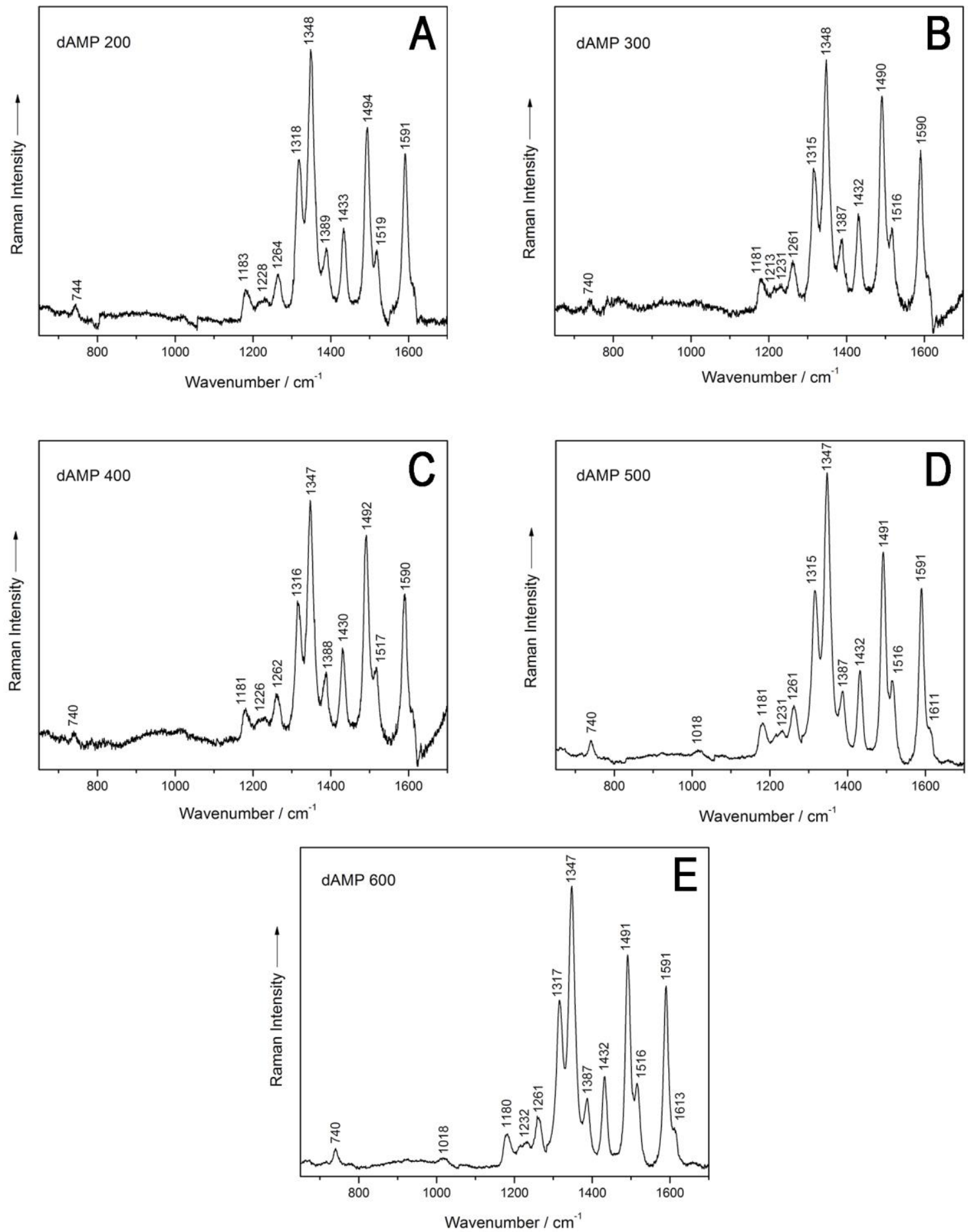

Fig. 1. The $275 \mathrm{~nm}$-excited UV resonance Raman spectra of dissolved 2'-deoxyadenosine-5'-monophosphate molecules in $10 \mathrm{mM}$ Bistris, $50 \mathrm{mM} \mathrm{NaCl}, p \mathrm{H}$ 6.4, at different concentrations: A. $200 \mu \mathrm{M}$; B. $300 \mu \mathrm{M}$; C. $400 \mu \mathrm{M}$; D. $500 \mu \mathrm{M}$; E. $600 \mu \mathrm{M}$.

Assuming a Lorentzian profile for the experimental band shape, a condition very often realized in solution, the fullwidths at half-maximum (fwhm) may be expressed by:

$$
\Delta v_{1 / 2}=(\mathrm{c} \pi \tau)^{-1}
$$

where $\tau$ is a "relaxation time" relative to all the relaxation processes contributing to the observed band profile, and $c$ is the velocity of light $[12,25]$.

Dynamical parameters associated with the investigated subpicosecond dynamics are presented in Table 1. Vibrational UVRR full-widths at half-maximum studied for the functional groups of dAMP molecules are to be found in the REV.CHIM.(Bucharest) $\bullet 1 \bullet$ no. $1 \bullet 2020$ 
wavenumber range $13-21 \mathrm{~cm}^{-1}$ and the corresponding global relaxations times $\tau$ are faster than $0.817 \mathrm{ps}$ and slower than $0.506 \mathrm{ps}$. In the case of dAMP relaxation processes in aqueous solutions, taking into account the values of the time dynamic parameter $\left(\tau_{\mathrm{UVRR}}\right)$, we can suppose that the dominant relaxation mechanism is the vibrational one.

Analyzing data in Table 1 on dAMP concentration, several remarks are to be done. For the band near $1318 \mathrm{~cm}^{-1}$

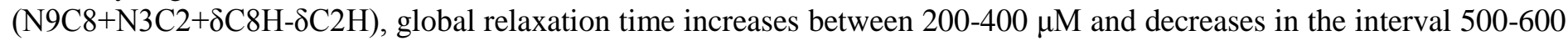
$\mu \mathrm{M}$. In the case of $1433 \mathrm{~cm}^{-1}(\mathrm{C} 4 \mathrm{~N} 9-\delta \mathrm{C} 8 \mathrm{H})$ vibrational profile, global relaxation time is equal to 0.758 ps at $200 \mu \mathrm{M}, 400$ $\mu \mathrm{M}$ and $600 \mu \mathrm{M}$ concentrations. As far as the mode near $1494 \mathrm{~cm}^{-1}(-\delta \mathrm{C} 2 \mathrm{H}-\mathrm{N} 9 \mathrm{C} 8+\delta \mathrm{C} 8 \mathrm{H})$ is concerned, the global relaxation time is equal to 0.685 ps at $200 \mu \mathrm{M}, 400 \mu \mathrm{M}, 500 \mu \mathrm{M}$ and $600 \mu \mathrm{M}$, respectively. A value of 0.708 ps was calculated for this profile, in the case of sample at $300 \mu \mathrm{M}$. Relaxation of this mode is the most stable for dAMP solution, with respect to its concentration. For the band around $1591 \mathrm{~cm}^{-1}(\mathrm{C} 5 \mathrm{C} 4-\mathrm{C} 4 \mathrm{~N} 3)$, the global relaxation time increases in the interval 200-300 $\mu \mathrm{M}$, decreases at $400 \mu \mathrm{M}$ and is equal to 0.708 ps for $500 \mu \mathrm{M}$ and $600 \mu \mathrm{M}$.

Table 1

TOTAL HALF BANDWIDTHS $\left(\mathrm{cm}^{-1}\right)$ OF UVRR VIBRATIONAL MARKERS AND GLOBAL RELAXATION TIMES OF FUNCTIONAL GROUPS, CHARACTERIZING dAMP MOLECULES AT DIFFERENT CONCENTRATIONS. UV RESONANCE RAMAN SPECTRA WERE EXCITED WITH A 275 nm LASER LINE

\begin{tabular}{|c|c|c|c|}
\hline$V_{\max }\left(\mathbf{c m}^{-1}\right)$ & $\Delta v_{1 / 2}\left(\mathrm{~cm}^{-1}\right)$ & $\tau_{\text {UVRR }}(\mathbf{p s})$ & Tentative assignment $[26,27]$ \\
\hline \multicolumn{4}{|c|}{ dAMP 200} \\
\hline 1318 & $19^{*} \pm 1$ & $0.559 \pm 0.029$ & $\mathrm{~N} 9 \mathrm{C} 8+\mathrm{N} 3 \mathrm{C} 2+\delta \mathrm{C} 8 \mathrm{H}-\delta \mathrm{C} 2 \mathrm{H}$ \\
\hline 1433 & $14 \pm 1$ & $0.758 \pm 0.054$ & C4N9- $\delta \mathrm{C} 8 \mathrm{H}$ \\
\hline 1494 & $15.5 \pm 1$ & $0.685 \pm 0.044$ & $-\delta \mathrm{C} 2 \mathrm{H}-\mathrm{N} 9 \mathrm{C} 8+\delta \mathrm{C} 8 \mathrm{H}$ \\
\hline 1591 & $14.2 \pm 1$ & $0.748 \pm 0.053$ & $\mathrm{C} 5 \mathrm{C} 4-\mathrm{C} 4 \mathrm{~N} 3$ \\
\hline \multicolumn{4}{|c|}{ dAMP 300} \\
\hline 1315 & $16^{*} \pm 1$ & $0.663 \pm 0.041$ & $\mathrm{~N} 9 \mathrm{C} 8+\mathrm{N} 3 \mathrm{C} 2+\delta \mathrm{C} 8 \mathrm{H}-\delta \mathrm{C} 2 \mathrm{H}$ \\
\hline 1432 & $15 \pm 1$ & $0.708 \pm 0.047$ & C4N9- $\delta \mathrm{C} 8 \mathrm{H}$ \\
\hline 1490 & $15 \pm 1$ & $0.708 \pm 0.047$ & $-\delta \mathrm{C} 2 \mathrm{H}-\mathrm{N} 9 \mathrm{C} 8+\delta \mathrm{C} 8 \mathrm{H}$ \\
\hline 1590 & $14 \pm 1$ & $0.758 \pm 0.054$ & $\mathrm{C} 5 \mathrm{C} 4-\mathrm{C} 4 \mathrm{~N} 3$ \\
\hline \multicolumn{4}{|c|}{ dAMP 400} \\
\hline 1316 & $15^{*} \pm 1$ & $0.708 \pm 0.047$ & $\mathrm{~N} 9 \mathrm{C} 8+\mathrm{N} 3 \mathrm{C} 2+\delta \mathrm{C} 8 \mathrm{H}-\delta \mathrm{C} 2 \mathrm{H}$ \\
\hline 1430 & $14 \pm 1$ & $0.758 \pm 0.054$ & $\mathrm{C} 4 \mathrm{~N} 9-\delta \mathrm{C} 8 \mathrm{H}$ \\
\hline 1492 & $15.5 \pm 1$ & $0.685 \pm 0.044$ & $-\delta \mathrm{C} 2 \mathrm{H}-\mathrm{N} 9 \mathrm{C} 8+\delta \mathrm{C} 8 \mathrm{H}$ \\
\hline 1590 & $14.5 \pm 1$ & $0.732 \pm 0.050$ & C5C4-C4N3 \\
\hline \multicolumn{4}{|c|}{ dAMP 500} \\
\hline 740 & $13.5 \pm 1$ & $0.786 \pm 0.058$ & $-\delta \mathrm{N} 7 \mathrm{C} 8 \mathrm{~N} 9-9 \mathrm{R}+\delta \mathrm{C} 5 \mathrm{~N} 7 \mathrm{C} 8+\mathrm{C} 4 \mathrm{~N} 9 \mathrm{C} 8$ \\
\hline 1181 & $21^{*} \pm 1$ & $0.506 \pm 0.024$ & $\mathrm{~N} 7 \mathrm{C} 8+\mathrm{N} 1 \mathrm{C} 2 ; \delta \mathrm{C} 6 \mathrm{NH}$ \\
\hline 1315 & $17^{*} \pm 1$ & $0.624 \pm 0.037$ & $\mathrm{~N} 9 \mathrm{C} 8+\mathrm{N} 3 \mathrm{C} 2+\delta \mathrm{C} 8 \mathrm{H}-\delta \mathrm{C} 2 \mathrm{H}$ \\
\hline 1432 & $14.5 \pm 1$ & $0.732 \pm 0.050$ & $\mathrm{C} 4 \mathrm{~N} 9-\delta \mathrm{C} 8 \mathrm{H}$ \\
\hline 1491 & $15.5 \pm 1$ & $0.685 \pm 0.044$ & $-\delta \mathrm{C} 2 \mathrm{H}-\mathrm{N} 9 \mathrm{C} 8+\delta \mathrm{C} 8 \mathrm{H}$ \\
\hline 1591 & $15 \pm 1$ & $0.708 \pm 0.047$ & C5C4-C4N3 \\
\hline \multicolumn{4}{|c|}{ dAMP 600} \\
\hline 740 & $13 \pm 1$ & $0.817 \pm 0.063$ & $-\delta \mathrm{N} 7 \mathrm{C} 8 \mathrm{~N} 9-9 \mathrm{R}+\delta \mathrm{C} 5 \mathrm{~N} 7 \mathrm{C} 8+\mathrm{C} 4 \mathrm{~N} 9 \mathrm{C} 8$ \\
\hline 1180 & $18^{*} \pm 1$ & $0.590 \pm 0.033$ & $\mathrm{~N} 7 \mathrm{C} 8+\mathrm{N} 1 \mathrm{C} 2 ; \delta \mathrm{C} 6 \mathrm{NH}$ \\
\hline 1317 & $19^{*} \pm 1$ & $0.559 \pm 0.029$ & $\mathrm{~N} 9 \mathrm{C} 8+\mathrm{N} 3 \mathrm{C} 2+\delta \mathrm{C} 8 \mathrm{H}-\delta \mathrm{C} 2 \mathrm{H}$ \\
\hline 1432 & $14 \pm 1$ & $0.758 \pm 0.054$ & $\mathrm{C} 4 \mathrm{~N} 9-\delta \mathrm{C} 8 \mathrm{H}$ \\
\hline 1491 & $15.5 \pm 1$ & $0.685 \pm 0.044$ & $-\delta \mathrm{C} 2 \mathrm{H}-\mathrm{N} 9 \mathrm{C} 8+\delta \mathrm{C} 8 \mathrm{H}$ \\
\hline 1591 & $15 \pm 1$ & $0.708 \pm 0.047$ & C5C4-C4N3 \\
\hline
\end{tabular}

* Low wavenumber side of the band was read; later on the respective profile was symmetrically analyzed. $\delta$ - bending mode

Experimental fwhm's of the UVRR bands vs square root of the dAMP concentrations are presented in Figure 2 for different vibrational modes $\left(1318 \mathrm{~cm}^{-1}, 1433 \mathrm{~cm}^{-1}, 1494 \mathrm{~cm}^{-1}\right.$ and $\left.1591 \mathrm{~cm}^{-1}\right)$. It is shown that the linear character is remarkably pronounced in the patterns of the changes in the bandwidths with the square roots of concentrations [20]. This linear relationship indicates that vibrational dephasing is probably the most efficient relaxation mechanism [11]. 

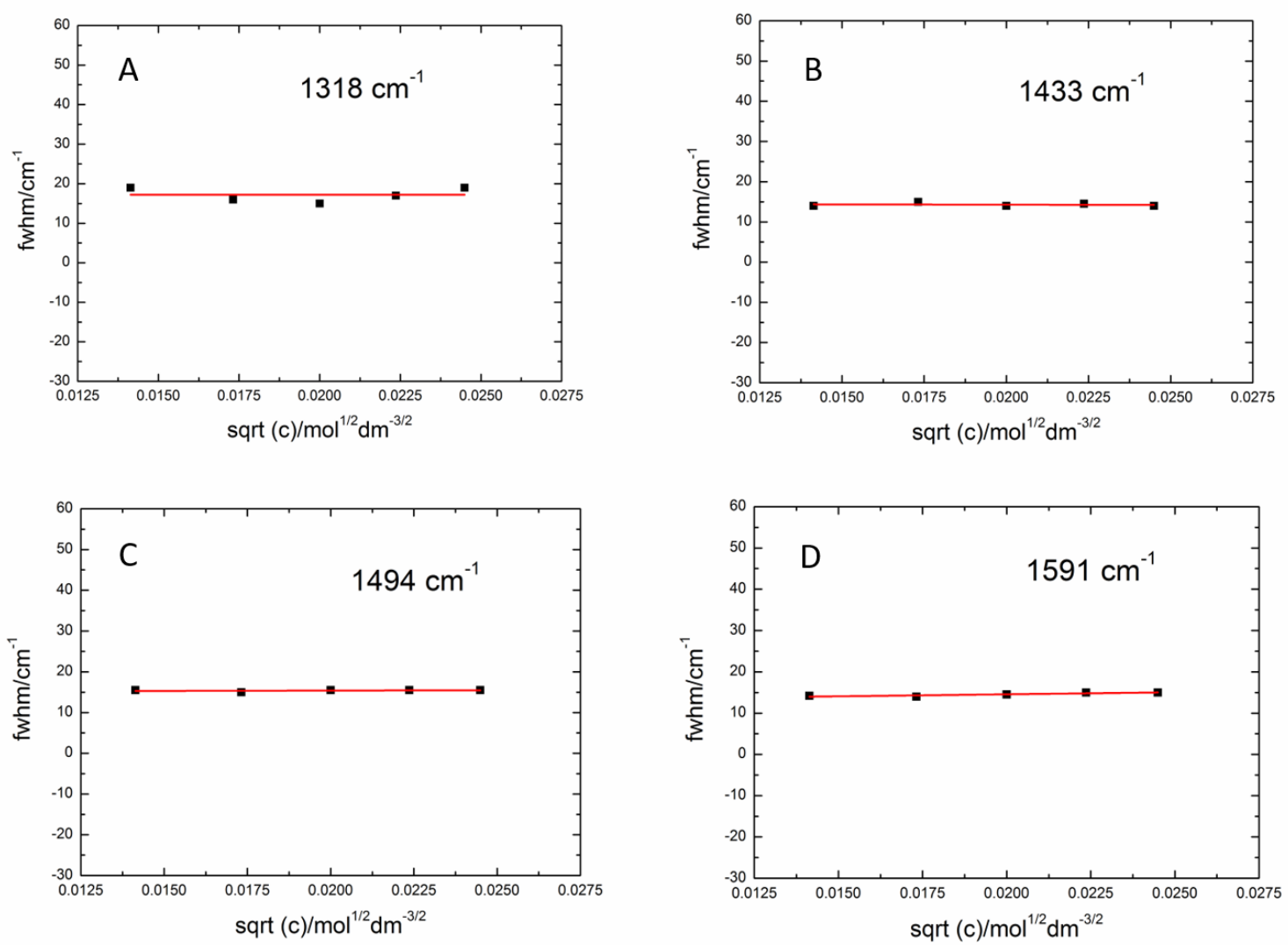

Fig. 2. Experimental fwhm's of the UVRR bands vs square root of the dAMP concentration, for the following vibrational modes: A. $1318 \mathrm{~cm}^{-1}$; B. $1433 \mathrm{~cm}^{-1}$; C. $1494 \mathrm{~cm}^{-1} ;$ D. $1591 \mathrm{~cm}^{-1}$

\section{Relaxation of the $1430 \mathrm{~cm}^{-1}(C 4 N 9-\delta C 8 H)$ oscillator of $d A M P$ in aqueous solutions. Experimental CF and its theoretical modelling}

The band near $1430 \mathrm{~cm}^{-1}(\mathrm{C} 4 \mathrm{~N} 9-\delta \mathrm{C} 8 \mathrm{H})$ in the UV resonance Raman spectrum of dAMP molecule, at the concentration of $400 \mu \mathrm{M}$ in aqueous solution, shows a fairly symmetric profile without shoulders or splitting (Fig. 1C). This mode allows additional dynamics analysis, namely vibrational band shape analysis through time correlation function (CF) concept. This data treatment is presented in the followings.

The main contribution to the experimental UVRR CF is of vibrational type, due to an adequate selection of the investigated system.

A comparison between natural logarithm of the UV resonance Raman correlation function (CF) for $1430 \mathrm{~cm}^{-1}(\mathrm{C} 4 \mathrm{~N}$ 9$\delta \mathrm{C} 8 \mathrm{H})$ band of dAMP, at about $400 \mu \mathrm{M}$ concentration in aqueous system and the natural logarithm of CFs corresponding to mathematical profiles Gauss and Lorentz (or Cauchy) having the same fwhm's as the experimental band, is presented in Figure 3. As seen in this figure, the experimental profile fits well with a Gauss one, with Lorentz (or Cauchy) corrections in its wings.

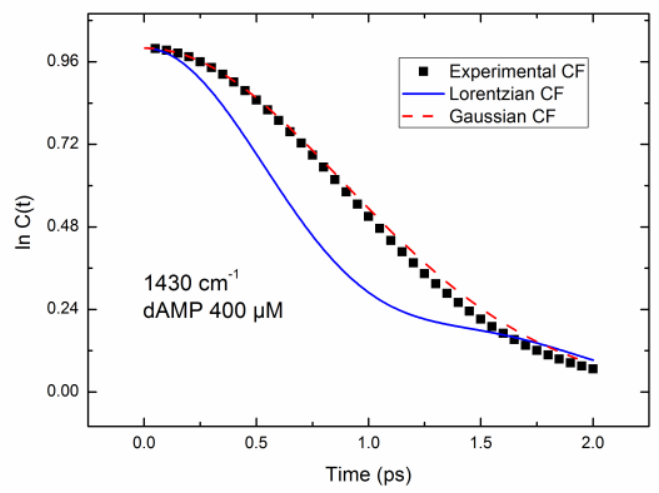

Fig. 3. The comparison between natural logarithm of the UV resonance Raman correlation function (CF) for 1430 $\mathrm{cm}^{-1}(\mathrm{C} 4 \mathrm{~N} 9-\delta \mathrm{C} 8 \mathrm{H})$ band of dAMP molecule, at about 400 $\mu \mathrm{M}$ concentration in aqueous solution and the natural logarithm of CFs corresponding to mathematical profiles with the same fwhm as the experimental band: black square - experimental CF; dash red line - Gaussian CF; blue line - Lorentzian (or Cauchy) $\mathrm{CF}$ 
Some models have been developed for vibrational dephasing, as one of the most important contribution to vibrational relaxation, based on Gaussian-Markovian theory [9,14,26-30]. According to Kubo-Rothschild's model the logarithm of the vibrational correlation function $\left[G_{v}(\mathrm{t})\right]$ is expressed by:

$$
\ln G_{v}(t)=-\left\langle\omega^{2}\right\rangle\left\{\tau_{c}^{2}\left[\exp \left(-t / \tau_{c}\right)-1\right]+\tau_{c} t\right\}
$$

where $\tau_{c}$ is the modulation time (time between collisions with the solvent) and $\left\langle\omega^{2}\right\rangle=4 \pi c^{2} M_{2}$ is the mean squared frequency displacement around the band centre.

Furthermore, Oxtoby [30] proposed another equation for this CF:

$$
\ln G_{v}(t)=-\left\langle\omega^{2}\right\rangle \tau_{c}^{2} \ln \cosh \left(-t / \tau_{c}\right)
$$

In the followings we will present for band near $1430 \mathrm{~cm}^{-1}$ the theoretical modelling of the natural logarithm of experimental CF with Kubo-Rotschild and Oxtoby models. Due to the fact that there is not a good coincidence between the experimental correlation function (ln CF) and the proposed theoretical models (Kubo-Rothschild and Oxtoby) by employing the experimental second moment, we tried to find the corresponding second band moment for which there is quite a superposition of the experimental correlation function (ln $\mathrm{CF}$ ) with the proposed models, respectively. So, the value of the modulation amplitude $\left(\left\langle\omega^{2}\right\rangle\right)$ was changed until a good coincidence between the natural logarithm of experimental CF and the vibrational dephasing models was obtained. The corresponding modulation time ( $\tau_{\mathrm{c}}$ for KuboRothschild and Oxtoby models, respectively) was obtained in each case. Besides, second band moments, a measure of the kinetic energy of the mode, were calculated with the following relationship: $\left.\mathrm{M}_{2}\left[\mathrm{~cm}^{-2}\right]=28.33<\omega_{2}\right\rangle$ [rad. $\left.\mathrm{ps}^{-2}\right]$.

In the next figures this mathematical procedure was applied. Deviations of the theoretical models as compared to the experimental profile, respectively, are to be observed in Figures 4-6. The best fit parameters have been found for Figures 7-8. Also, the spectral and relaxation parameters corresponding to the $1430 \mathrm{~cm}^{-1}$ UVRR vibrational profile for the dAMP $(400 \mu \mathrm{M})$ sample, are presented in Table 2. Analyzing the values of the modulation speed in this table, a slow modulation regime of the vibrational frequencies is to be observed. Better fits are to be observed upon decreasing of $\left\langle\omega^{2}\right\rangle$. KuboRothschild's model fits better than Oxtoby's one the experimental correlation function (ln CF) for values of the modulation amplitude $\left.\left(<\omega^{2}\right\rangle\right)$ ranging between 1.5-1.41 rad. $\mathrm{ps}^{-2}$.
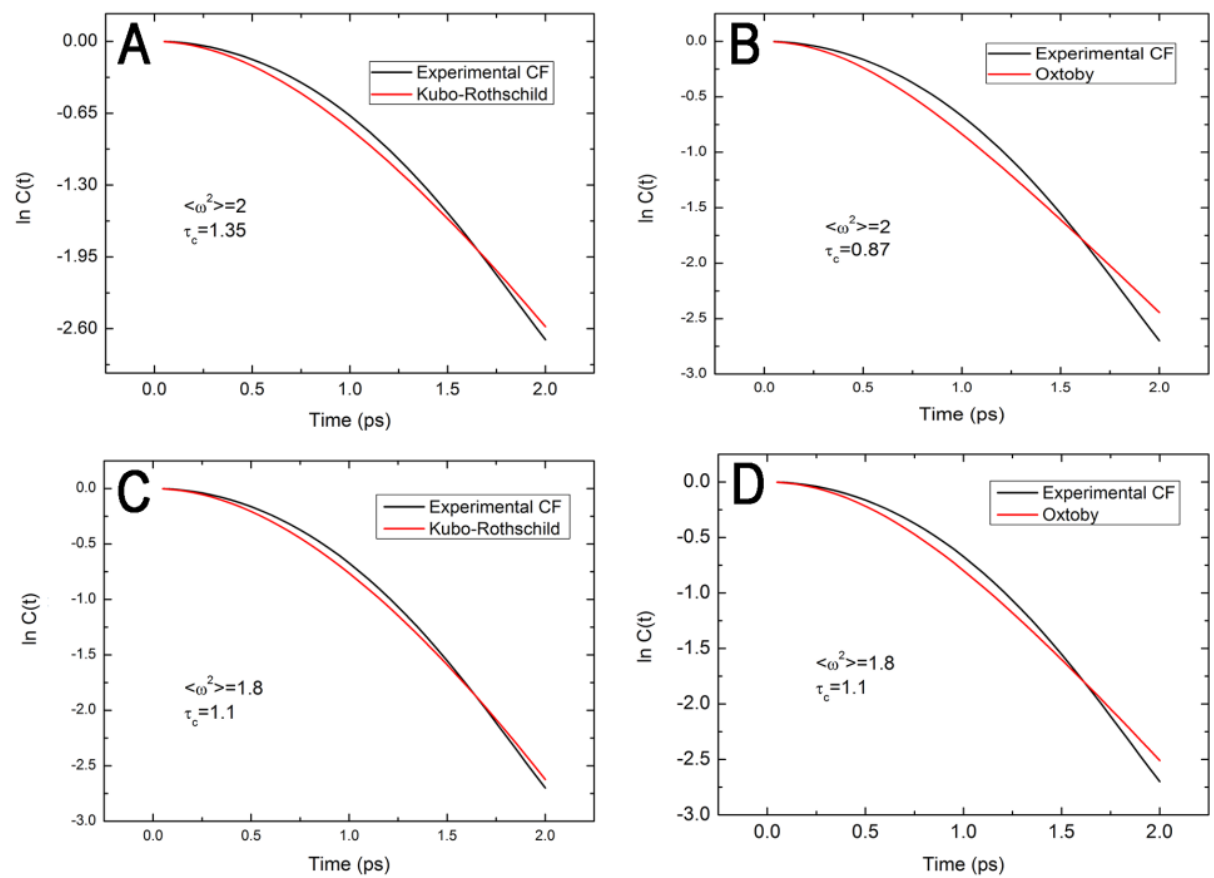

Fig. 4. The comparison between natural logarithm of the UV resonance Raman correlation function (CF) for $1430 \mathrm{~cm}^{-1}$

(C4N9- $\delta \mathrm{C} 8 \mathrm{H}$ ) band of dAMP molecule, at about $400 \mu \mathrm{M}$ concentration in aqueous solution (black line) and A. Kubo-Rothschild's fitted equation (red line): $\left\langle\omega^{2}\right\rangle=2$ and $\tau_{c}=1.35$; B. Oxtoby's fitted equation (red line): $\left\langle\omega^{2}\right\rangle=2$ and $\tau_{c}=0.87$; C. Kubo-Rothschild's fitted equation (red line): $\left\langle\omega^{2}\right\rangle=1.8$ and $\tau_{\mathrm{c}}=1.1$; D. Oxtoby's fitted equation (red line): $\left\langle\omega^{2}\right\rangle=1.8$ and $\tau_{\mathrm{c}}=1.1$

For the modulation amplitude $\left\langle\omega^{2}\right\rangle=1.40 \mathrm{rad} . \mathrm{ps}^{-2}$, both Kubo-Rothschild and Oxtoby models fit well the experimental correlation function (ln CF). 

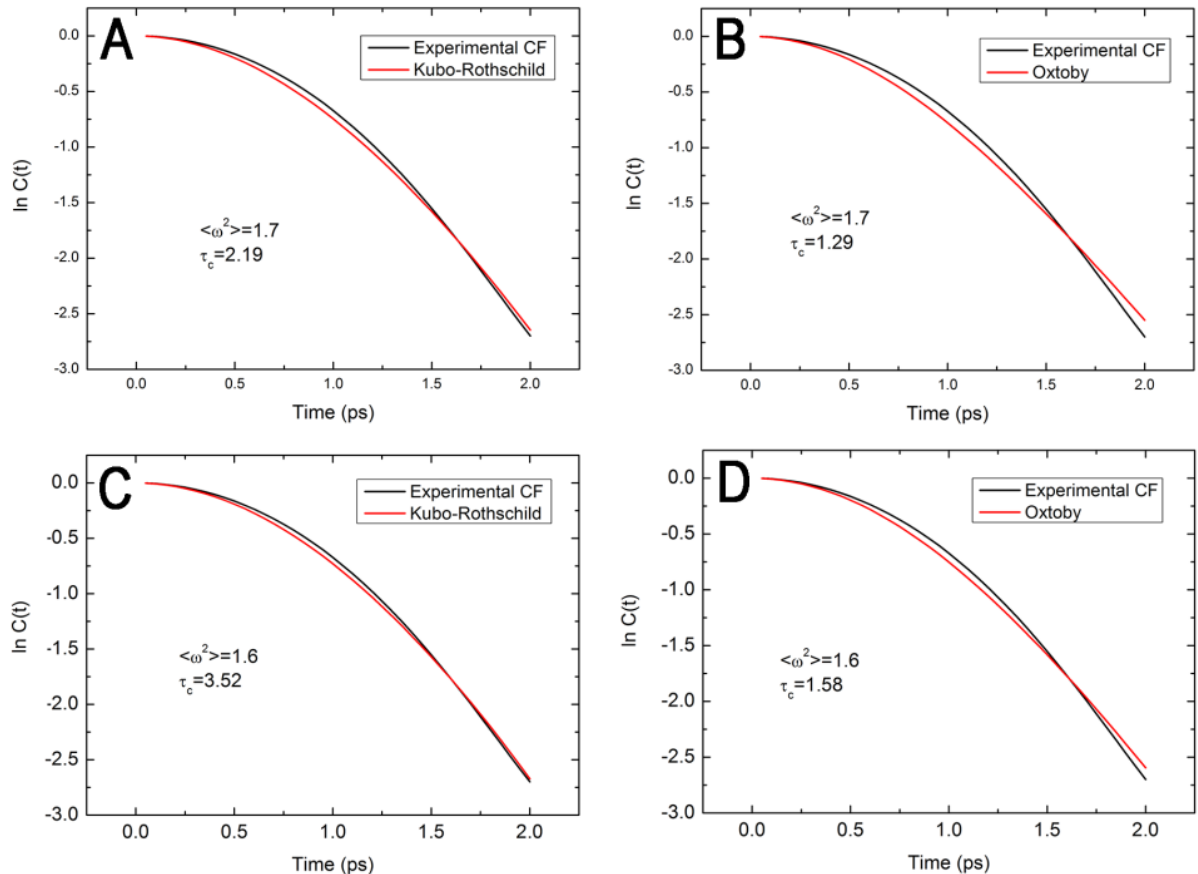

Fig. 5. The comparison between natural logarithm of the UV resonance Raman correlation function (CF) for $1430 \mathrm{~cm}^{-1}$ $(\mathrm{C} 4 \mathrm{~N} 9-\delta \mathrm{C} 8 \mathrm{H}$ ) band of dAMP molecule, at about $400 \mu \mathrm{M}$ concentration in aqueous solution (black line) and A.Kubo-Rothschild's fitted equation (red line): $\left\langle\omega^{2}\right\rangle=1.7$ and $\tau_{\mathrm{c}}=2.19$; B. Oxtoby's fitted equation (red line): $\omega^{2}>=1.7$ and $\tau_{c}=1.29 ;$ C. Kubo-Rothschild's fitted equation (red line): $<\omega^{2}>=1.6$ and $\tau_{c}=3.52$;

D. Oxtoby's fitted equation (red line): $\left\langle\omega^{2}\right\rangle=1.6$ and $\tau_{\mathrm{c}}=1.58$

We have found, that upon lowering the kinetic energy stored in this mode, a more efficient vibrational excitation energy transfer from the molecular group to the neighbourhood is obtained. The best fit parameters are connected with the most efficient relaxation mechanism-vibrational dephasing or population relaxation, characterizing biomolecular interactions. The efficiency of this energetic transfer is connected with the biological function of DNA and its components. For example, the respective mode $\left[1430 \mathrm{~cm}^{-1}(\mathrm{C} 4 \mathrm{~N} 9-\delta \mathrm{C} 8 \mathrm{H})\right]$, as an energy carrier, might play an important role in molecular recognition or in other interactions of dAMP molecule.
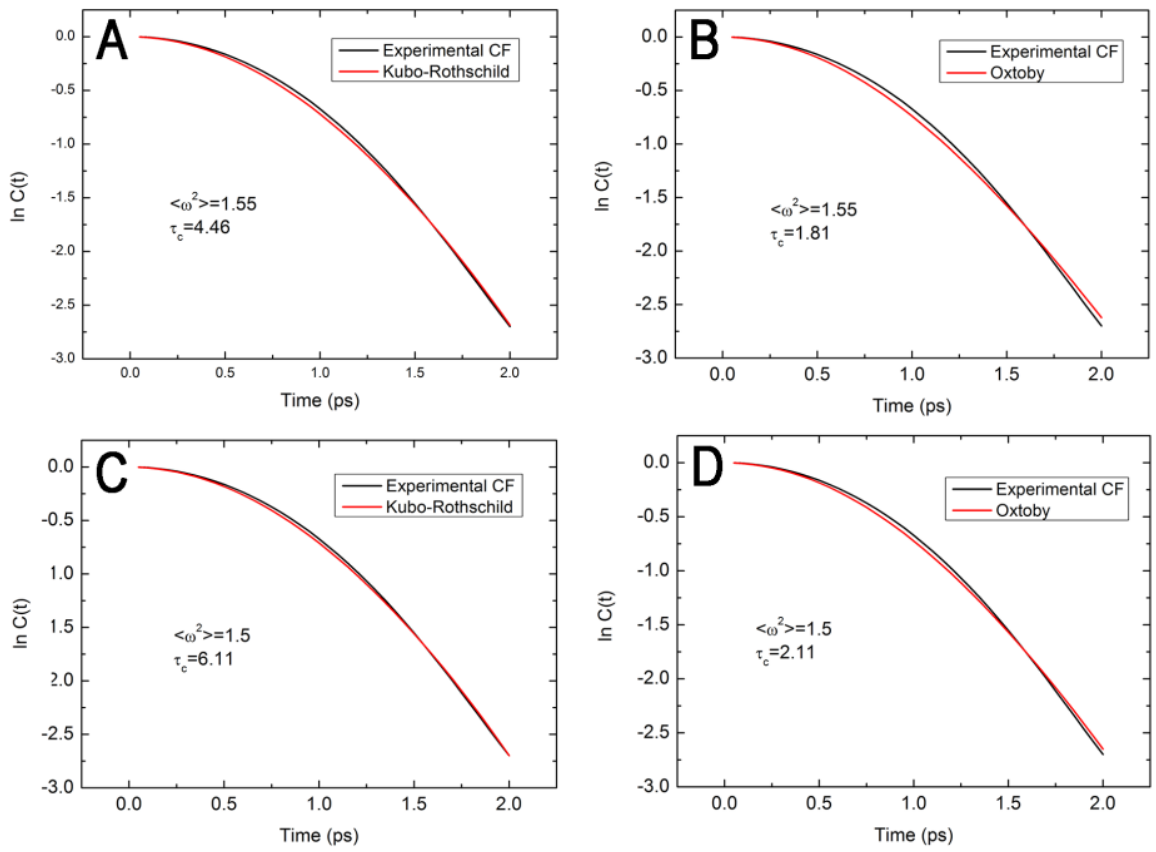

Fig. 6. The comparison between natural logarithm of the UV resonance Raman correlation function (CF) for $1430 \mathrm{~cm}^{-1}$

$(\mathrm{C} 4 \mathrm{~N} 9-\delta \mathrm{C} 8 \mathrm{H})$ band of dAMP molecule, at about $400 \mu \mathrm{M}$ concentration in aqueous solution (black line) and A. Kubo-Rothschild's

fitted equation (red line): $\left\langle\omega^{2}\right\rangle=1.55$ and $\tau_{\mathrm{c}}=4.46$; B. Oxtoby's fitted equation (red line): $\left\langle\omega^{2}\right\rangle=1.55$ A.and $\tau_{\mathrm{c}}=1.81$; C. Kubo-Rothschild's fitted equation (red line): $\left\langle\omega^{2}\right\rangle=1.5$ and $\tau_{c}=6.11$; D. Oxtoby's fitted equation (red line): $\left\langle\omega^{2}\right\rangle=1.5$ and $\tau_{c}=2.11$. 

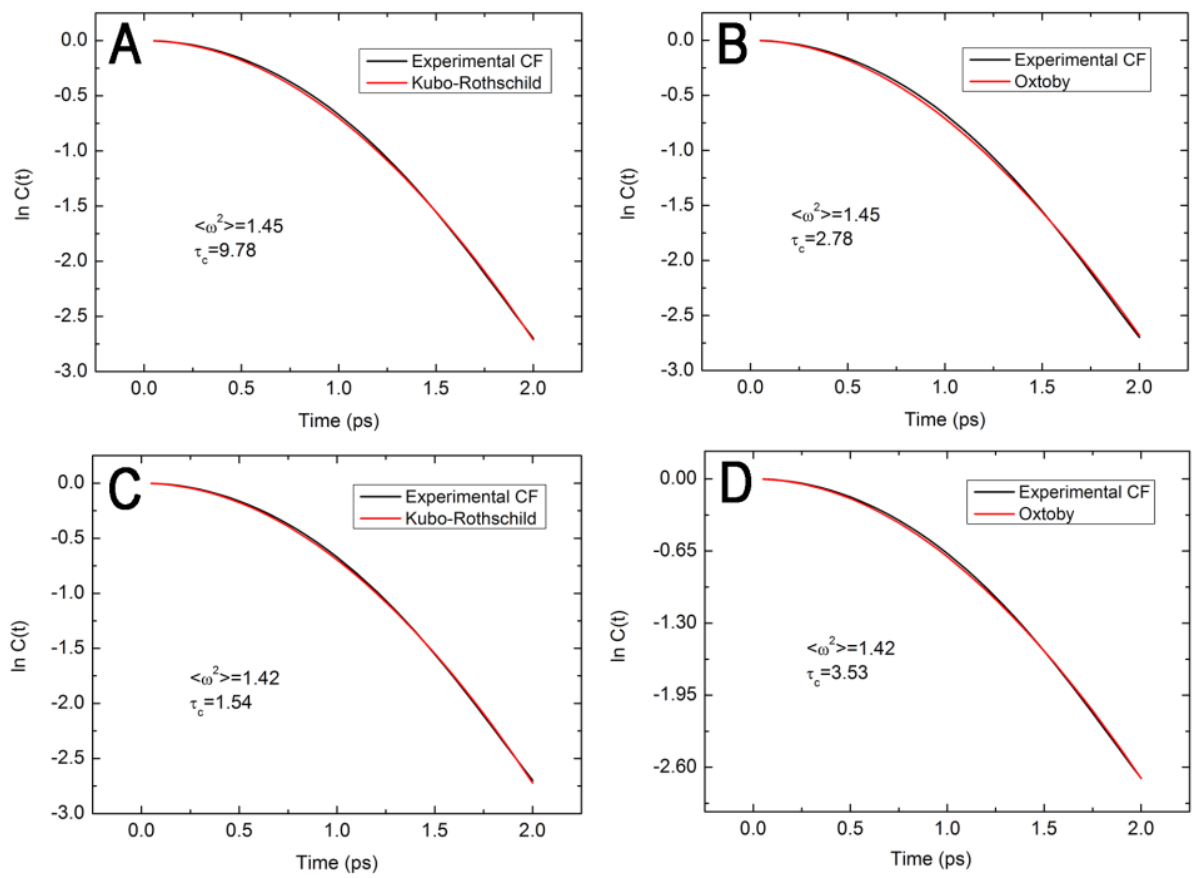

Fig. 7. The comparison between natural logarithm of the UV resonance Raman correlation function (CF) for $1430 \mathrm{~cm}^{-1}(\mathrm{C} 4 \mathrm{~N} 9-\delta \mathrm{C} 8 \mathrm{H})$ band of dAMP molecule, at about $400 \mu \mathrm{M}$ concentration in aqueous solution (black line) and A. Kubo-Rothschild's fitted equation (red line): $\left\langle\omega^{2}\right\rangle=1.45$ and $\tau_{\mathrm{c}}=9.78$; B. Oxtoby's fitted equation (red line): $\left\langle\omega^{2}\right\rangle=1.45$ and $\tau_{\mathrm{c}}=2.78$; C. Kubo-Rothschild's fitted equation (red line): $\left\langle\omega^{2}\right\rangle=1.42$ and $\tau_{\mathrm{c}}=1.54$; D. Oxtoby's fitted equation (red line): $\left\langle\omega^{2}\right\rangle=1.42$ and $\tau_{\mathrm{c}}=3.53$
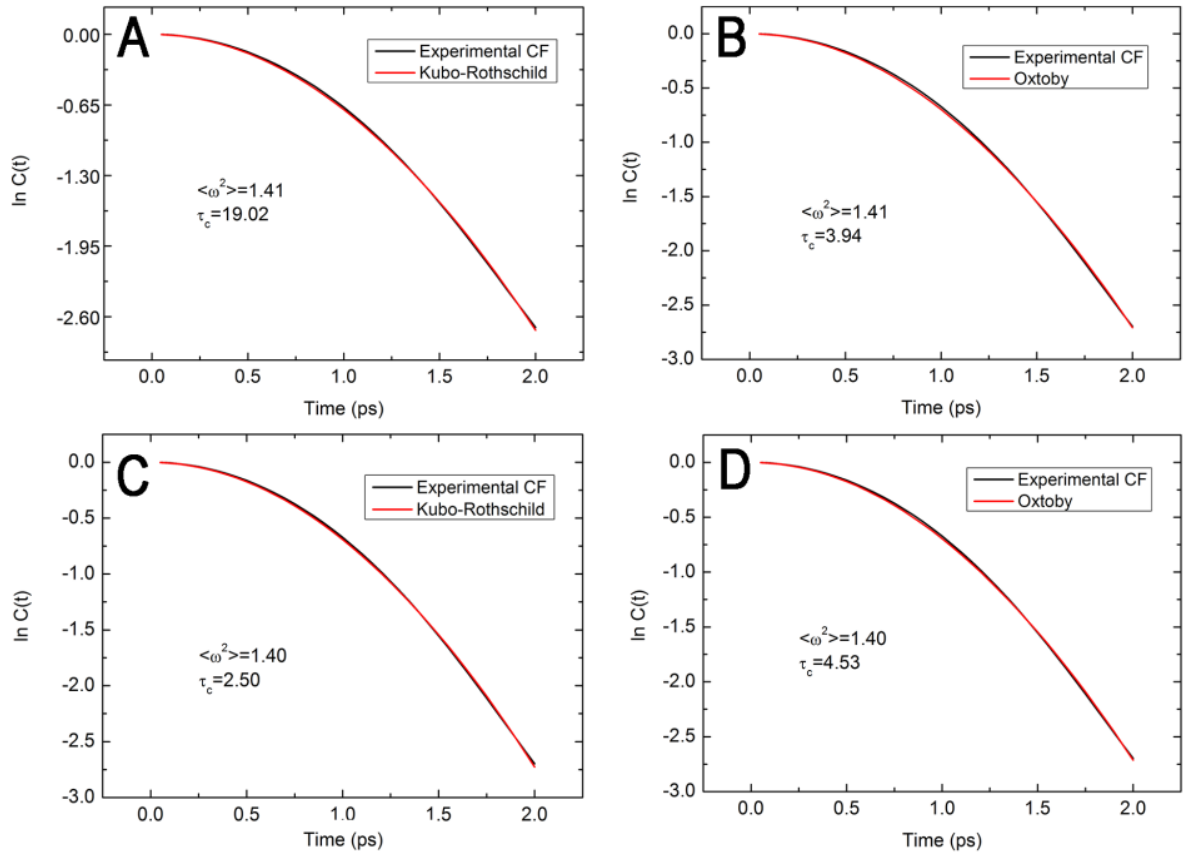

Fig. 8. The comparison between natural logarithm of the UV resonance Raman correlation function (CF) for $1430 \mathrm{~cm}^{-1}$ (C4N9- $\delta \mathrm{C} 8 \mathrm{H})$ band of dAMP molecule, at about $400 \mu \mathrm{M}$ concentration in aqueous solution (black line) and A. Kubo-Rothschild's fitted equation (red line): $\left\langle\omega^{2}\right\rangle=1.41$ and $\tau_{\mathrm{c}}=19.02$; B. Oxtoby's fitted equation (red line): $\left\langle\omega^{2}\right\rangle=1.41$ and $\tau_{c}=3.94$; C. Kubo-Rothschild's fitted equation (red line): $\left\langle\omega^{2}\right\rangle=1.40$ and $\tau_{c}=2.50$;

D. Oxtoby's fitted equation (red line) $n:<\omega^{2}>=1.40$ and $\tau_{c}=4.53$ 
Table 2

THE SPECTRAL AND RELAXATION PARAMETERS, CORRESPONDING TO THE $1430 \mathrm{~cm}^{-1}$ UVRR VIBRATIONAL PROFILE,

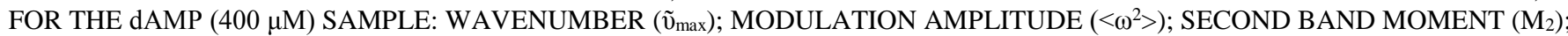
RELAXATION TIME CALCULATED BY INTEGRATING THE EXPERIMENTAL CF $\left(\tau^{\mathrm{UVRR}}{ }_{\mathrm{CF}}\right)$; MODULATION SPEED $\left(<\omega^{2}>1 / 2 \tau_{\mathrm{c}}\right.$ FOR KUBO-ROTHSCHILD AND OXTOBY MODELS, RESPECTIVELY); MODULATION TIME ( $\tau_{c}$ for KUBO-ROTHSCHILD

AND OXTOBY MODELS, RESPECTIVELY)

\begin{tabular}{|c|c|c|c|c|c|c|c|}
\hline $\begin{array}{c}\tilde{\mathbf{v}}_{\max } \\
\left(\mathrm{cm}^{-1}\right)\end{array}$ & $\begin{array}{c}\left\langle\omega^{2}\right\rangle \\
\left(\mathrm{rad} . \mathrm{ps}^{-2}\right)\end{array}$ & $\begin{array}{c}\mathbf{M}_{2} \\
\left(\mathrm{~cm}^{-2}\right)\end{array}$ & $\tau^{\mathrm{UVRR}_{\mathrm{CF}}(\mathrm{ps})}$ & $\left\langle\omega^{2}\right\rangle^{1 / 2} \tau_{\mathrm{c}}{ }^{\mathrm{KR}}$ & $\left\langle\omega^{2}\right\rangle^{1 / 2} \tau_{c}{ }^{O x}$ & $\begin{array}{l}\tau_{\mathrm{c}^{\mathrm{KR}}} \\
(\mathrm{ps})\end{array}$ & $\tau_{\mathrm{c}}{ }^{\mathrm{Ox}}(\mathrm{ps})$ \\
\hline 1430 & 2 & 56.66 & 0.943 & 1.91 & & 1.35 & \\
\hline 1430 & 2 & 56.66 & 0.943 & & 1.23 & & 0.87 \\
\hline 1430 & 1.8 & 50.99 & 0.943 & 1.48 & & 1.10 & \\
\hline 1430 & 1.8 & 50.99 & 0.943 & & 1.48 & & 1.10 \\
\hline 1430 & 1.7 & 48.16 & 0.943 & 2.85 & & 2.19 & \\
\hline 1430 & 1.7 & 48.16 & 0.943 & & 1.68 & & 1.29 \\
\hline 1430 & 1.6 & 45.33 & 0.943 & 11.98 & & 3.52 & \\
\hline 1430 & 1.6 & 45.33 & 0.943 & & 1.99 & & 1.58 \\
\hline 1430 & 1.55 & 43.91 & 0.943 & 5.55 & & 4.46 & \\
\hline 1430 & 1.55 & 43.91 & 0.943 & & 2.25 & & 1.81 \\
\hline 1430 & 1.50 & 42.49 & 0.943 & 7.48 & & 6.11 & \\
\hline 1430 & 1.50 & 42.49 & 0.943 & & 2.58 & & 2.11 \\
\hline 1430 & 1.45 & 41.08 & 0.943 & 11.77 & & 9.78 & \\
\hline 1430 & 1.45 & 41.08 & 0.943 & & 3.35 & & 2.78 \\
\hline 1430 & 1.42 & 40.23 & 0.943 & 1.84 & & 1.54 & \\
\hline 1430 & 1.42 & 40.23 & 0.943 & & 4.21 & & 3.53 \\
\hline 1430 & 1.41 & 39.94 & 0.943 & 22.58 & & 19.02 & \\
\hline 1430 & 1.41 & 39.94 & 0.943 & & 4.68 & & 3.94 \\
\hline 1430 & 1.40 & 39.66 & 0.943 & 2.95 & & 2.50 & \\
\hline 1430 & 1.40 & 39.66 & 0.943 & & 5.36 & & 4.53 \\
\hline
\end{tabular}

\section{Conclusions}

In this work relaxation processes of functional groups, characterizing 2'-deoxyadenosine-5'-monophosphate (dAMP) compound, were investigated as a function of nucleotide concentration, in aqueous solution $(200-600 \mu \mathrm{M})$, by UV resonance Raman spectroscopy (UVRR). The full-widths at half-maximum (fwhm's) studied in this case vary between 13 $-21 \mathrm{~cm}^{-1}$ and the corresponding global relaxation times were found in the range $0.506-0.817 \mathrm{ps}$. Also, the sensitivity of half bandwidths to 2'-deoxyadenosine-5'-monophosphate concentration was analyzed. For aqueous solutions of dAMP molecules, we can suppose that the dominant relaxation mechanism is the vibrational one. From various vibrational relaxation mechanisms, vibrational dephasing seems to be the most important, as indicated from the linear relationship between the true fwhm's and the square roots of concentrations.

Also, the $1430 \mathrm{~cm}^{-1}$ UVRR band corresponding to $v(\mathrm{C} 4 \mathrm{~N} 9-\delta \mathrm{C} 8 \mathrm{H})$ oscillator of dAMP molecule in aqueous solution $(400 \mu \mathrm{M})$, was selected for band shape analysis. Vibrational dephasing accomplishes an efficient vibrational relaxation of this mode. Theoreticals models (Kubo-Rothschild and Oxtoby) for this process have yielded significant relaxation parameters. The value of the modulation amplitude $\left(\left\langle\omega^{2}\right\rangle\right)$ was changed until a good coincidence between the experimental correlation function (ln $\mathrm{CF}$ ) and the vibrational dephasing models was obtained, respectively. The best fit parameters are connected with the most efficient relaxation mechanism-vibrational dephasing or population relaxation, characterizing biomolecular interactions. To our knowledge this is the first UVRR study on nucleotide vibrational band shape analysis through time correlation function concept.

This analysis might be used in future studies concerning analogous compounds of DNA and RNA constituents obtained by synthesis, having biological or medical relevance, in particular with an anticancer, antiviral and antibacterial activity.

Acknowledgements: The authors wish to thank to Prof. Dr. Sebastian Schlücker (University of Duisburg-Essen, Essen, Germany) for facilitating the UV resonance Raman spectroscopic measurements at the University of Osnabrück, Osnabrück, Germany and to Dr. Stephan Niebling (University of Hamburg, Center for Ultrafast Imaging, Hamburg, Germany) for useful discussions on UV resonance Raman technique. Financial support from DAAD - Deutscher Akademischer Austauschdienst, Germany (Section 322, Codenumber: A/11/05349) is gratefully acknowledged by C.M.M. This work was partially supported by a grant of Ministry of National Education, National Authority for Scientific Research CNCS - UEFISCDI, Romania, project code PN-II-ID-PCE-2012-4-0115. 


\section{References}

1. KUMAR PAL, S., PEON, J., ZEWAIL, A.H., Chem. Phys. Lett., 363, 2002, p. 57; Ultrafast decay and hydration dynamics of DNA bases and mimics.

2. DEVI, T.G., UPADHAYAY, G., Spectrochim. Acta A: Molec. and Biomolec. Spectrosc., 91, 2012, p. 106; Solvent dependent Raman bandshape analysis on $\mathrm{C}=\mathrm{O}$ containing molecules: Vibrational relaxation study.

3. RABADANOV, K.S., GARUFOV, M.M., ALIEV, A.R., AKHMEDOV, I.R., KAKAGASANOV, M.G., KIRILLOV, S.A., Russ. Metall.+, 8, 2011, p. 760; Vibrational dephasing of the perchlorate ion in an $\mathrm{LiClO}_{4}$ melt.

4. RAMAKRISHNAN, V., SARUA, A., KUBALL, M., ABDULLAH, A.F., J. Raman Spectrosc., 41, 2010, p. 320; Raman spectroscopic studies of vibrational relaxation and non-coincidence effect in substituted benzaldehyde binary mixtures.

5. GIORGINI, M.G., ARCIONI, A., POLIZZI, C., MUSSO, M., OTTAVIANI, P., J. Chem. Phys., 120, 2004, p. 4969; Relaxation processes of the liquid crystal ME6N in the isotropic phase studied by Raman scattering experiments.

6. KALAMPOUNIAS, A.G., TSILOMELEKIS, G., BOGHOSIAN, S., J. Mol. Liq., 198, 2014, p. 299; Unraveling the role of microenvironment and hydrodynamic forces on the vibrational relaxation rates of pyridine-water complexes.

7. KALAMPOUNIAS, A.G., J. Mol. Liq., 202, 2015, p. 68; Dilution effect on the vibrational frequency and vibrational relaxation of $\mathrm{PbCl}_{2}-\mathrm{KCl}$ ionic liquids.

8. KOZICH, V., SZYC, Ł., NIBBERING, E.T.J., WERNCKE, W., ELSAESSER, T., Chem. Phys. Lett., 473, 2009, p. 171; Ultrafast redistribution of vibrational energy after excitation of NH stretching modes in DNA oligomers.

9. HERNANZ, A., BRATU, I., NAVARRO, R., J. Phys. Chem. B, 108, 2004, p. 2438; IR study on the relaxation of the phosphate group of 5'-dCMP in ${ }^{2} \mathrm{H}_{2} \mathrm{O}$ and $\mathrm{H}_{2} \mathrm{O}$ solutions.

10. HERNANZ, A., BRATU, I., NAVARRO, R., HUVENNE, J.P., LEGRAND, P., J. Chem. Soc. Farad. Trans., 92, 1996, p. 1111; IR study of the symmetric $v_{\mathrm{s}}\left(\mathrm{PO}_{3}{ }^{2-}\right)$ mode of 5'-CMP in $\mathrm{H}_{2} \mathrm{O}$ solution. Relaxation of the phosphate group.

11. NAVARRO, R., BRATU, I., HERNANZ, A., J. Phys. Chem., 97, 1993, p. 9081; FTIR study of the symmetric $v_{\mathrm{s}}\left(\mathrm{PO}_{3}{ }^{2-}\right)$ mode of 5'-CMP in heavy water solution: molecular relaxation processes.

12. HERNANZ, A., BRATU, I., GAVIRA-VALLEJO, J.M., In Insights into Vibrational Spectroscopy of Nucleic Acids and their Complexes; Muntean, C. M., Bratu, I., Eds.; Transworld Research Network: Kerala, 2009; p. 29-46.

13. MUNTEAN, C.M., BRATU, I., Spectroscopy, 21, 2007, p. 193; Molecular dynamics in calf-thymus DNA, at neutral and low pH, in the presence of $\mathrm{Na}^{+}, \mathrm{Ca}^{2+}$ and $\mathrm{Mg}^{2+}$ ions: a Raman microspectroscopic study.

14. MUNTEAN, C.M., BRATU, I., HERNANZ, A., J. Phys. Chem. B, 121, 2017, p. 6909; Vibrational relaxation of the backbone and base modes in LacDNA complexes by UV resonance Raman spectroscopy.

15. ZHANG, T., MA, H., NIU, Y., LI, W., WANG, D., PENG, Q., SHUAI, Z., LIANG, W.Z., J. Phys. Chem. C, 119, 2015, p. 5040; Spectroscopic signature of the aggregation-induced emission phenomena caused by restricted nonradiative decay: A theoretical proposal.

16. SING, C.E., OLVERA DE LA CRUZ, M., MARKO, J.F., Nucleic Acids Res., 42, 2014, p. 3783; Multiple-binding-site mechanism explains concentration-dependent unbinding rates of DNA-binding proteins.

17. MISKOVSKY, P., CHINSKY, L., LAIGLE, A., TURPIN, P.Y., J. Biomol. Struct. Dyn., 6, 1989, p. 915; The Concentration Dependence of the Right to Left Conformational Transition in Natural DNA Identified by Raman Spectroscopy.

18. PALACKÝ, J., VORLÍČKOVÁ, M., KEJNOVSKÁ, I., MOJZEŠ, P., Nucleic Acids Res., 41, 2013, p. 1005; Polymorphism of human telomeric quadruplex structure controlled by DNA concentration: A Raman study.

19. SIDOROVA, N.Y., SCOTT, T., RAU, D.C., Biophys. J., 104, 2013, p. 1296; DNA Concentration-Dependent Dissociation of EcoRI: Direct Transfer or Reaction during Hopping.

20. HIGUCHI, S., TANAKA, S., Spetrochim. Acta, 31A, 1975, p. 1003; Experimental investigations on the concentration-dependences of the halfband widths of $\mathrm{NO}_{2}$ symmetric stretching vibration bands.

21. MUNTEAN, C.M., SALEHI, M., NIEBLING, S., WALKENFORT, B., J. Raman Spectrosc., 44, 2013, p. 1693; The influence of divalent metal ions on low $\mathrm{pH}$ induced LacDNA structural changes as probed with UV resonance Raman spectroscopy.

22. PRIMERA-PEDROZO, O.M., DEL MAR RODRÍGUEZ, G., CASTELLANOS, J., FELIX-RIVERA, H., RESTO, O., HERNÁNDEZ-RIVERA, S.P., Spectrochim. Acta A: Molec. and Biomolec. Spectrosc., 87, 2012, p. 77; Increasing surface enhanced Raman spectroscopy effect of RNA and DNA components by changing the $\mathrm{pH}$ of silver colloidal suspensions.

23. KONOROV, S.O., SCHULZE, H.G., ADDISON, C.J., HAYNES, C.A., BLADES, M.W., TURNER, R.F.B., J. Raman Spectrosc., 40, 2009, p. 1162; Ultraviolet resonance Raman spectroscopy of locked single-stranded oligo(dA) reveals conformational implications of the locked ribose in LNA.

24. FODOR, P.A.S., RAVA, R.P., HAYS, T.R., SPIRO, T.G., J. Am. Chem. Soc., 107, 1985, p. 1520; Ultraviolet resonance Raman spectroscopy of the nucleotides with 266-, 240-, 218-, and 200-nm pulsed laser excitation.

25. ROTHSCHILD, W.G., Dynamics of Molecular Liquids; Wiley: New York, 1984.

26. ROTHSCHILD, W.G., J. Chem. Phys., 65, 1976, p. 455; Motional characteristics of large molecules from their Raman and infrared band contours: Vibrational dephasing.

27. ANDERSON, P.W., J. Phys. Soc. Jpn., 9, 1954, p. 316; A mathematical model for the narrowing of spectral lines by exchange or motion.

28. KUBO, R., In Fluctuation, Relaxation, and Resonance in Magnetic Systems; Ter Haar, D., Ed.; Oliver and Boyd: Edinburgh, UK, 1962 , p. 23 68.

29. CONSTANT, M., FAUQUEMBERGUE, R., J. Chem. Phys., 58, 1973, p. 4030; Raman scattering. I. Vibrational correlation in methyl iodide. 30. OXTOBY, D.W., J. Chem. Phys., 74, 1981, p. 1503; A useful interpolation between static and motional narrowing limits for vibrational dephasing.

$\overline{\text { Manuscript received: 22.03.2019 }}$ 